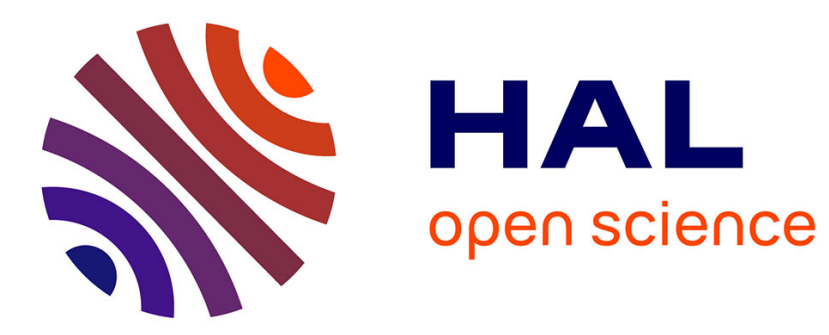

\title{
Numerical Simulation of Ultrasonic Surface Treatment
}

\author{
R. Balokhonov, P. Makarov, V. Romanova
}

\section{To cite this version:}

R. Balokhonov, P. Makarov, V. Romanova. Numerical Simulation of Ultrasonic Surface Treatment. Journal de Physique IV Proceedings, 1997, 07 (C3), pp.C3-55-C3-60. 10.1051/jp4:1997312 . jpa00255405

\section{HAL Id: jpa-00255405 https://hal.science/jpa-00255405}

Submitted on 1 Jan 1997

HAL is a multi-disciplinary open access archive for the deposit and dissemination of scientific research documents, whether they are published or not. The documents may come from teaching and research institutions in France or abroad, or from public or private research centers.
L'archive ouverte pluridisciplinaire HAL, est destinée au dépôt et à la diffusion de documents scientifiques de niveau recherche, publiés ou non, émanant des établissements d'enseignement et de recherche français ou étrangers, des laboratoires publics ou privés. 


\title{
Numerical Simulation of Ultrasonic Surface Treatment
}

\author{
R.R. Balokhonov, P.V. Makarov and V.A. Romanova
}

Institute of Strength Physics and Materials Science, Siberian Branch of Russian Academy of Sciences, pr. Academichesky 2/1, 634021 Tomsk, Russia

\begin{abstract}
A dynamic model for the behavior of ultrasonically treatment materials is suggested. The microplastic strain piling up is related to the redistribution of the available defects and emergence of new ones on the microscale level as well as to the evolution of the available substructures and formation of new ones on the mesoscale level. The behavior of mild steel specimens subjected to ultrasonic shock wave treatment and to machining where the ultrasonic vibrations are applied directly by concentrator or magnetostrictive converter has been evaluated. The results obtained are reported.
\end{abstract}

\section{INTRODUCTION}

It is well known that complicated irreversible processes (hardening, plastic deformation development and, finally, - fracture), which are attributed to material evolution on different structural levels, go on under powerful ultrasonic treatment. There are several regimes of ultrasonic treatment differed in geometry of the treatment, ultrasound supply, stress level under loading, etc.

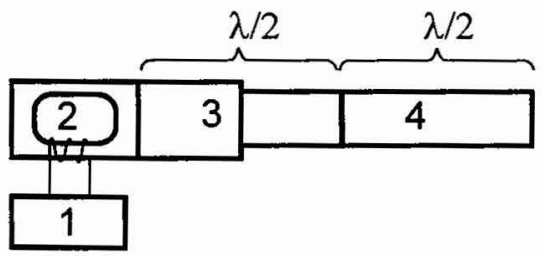

a)

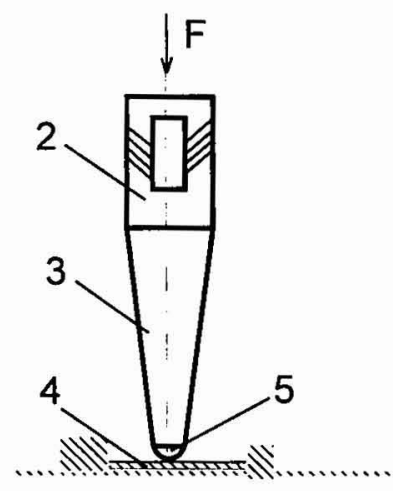

b)

Figure 1: Configurations of ultrasonic treatment, where 1 is electric generator, 2 is magneto-strictional transformer, 3 is ultrasonic concentrator, 4 is specimen under treatment, 5 is deforming tool.

Mathematical model allowing to describe the materials response to ultrasonic treatment at different regimes were proposed by the authors in [1,2] not taking into account the phase transformations and temperature influence. In the present work the results of numerical simulations of materials behavior under ultrasonic treatment of two different types are presented. At the first regime the ultrasonic vibrations are applied directly by concentrator or magnetostrictive converter. The second regime is the ultrasonic shock treatment. 


\section{MATHEMATICAL DEFINITION}

The main dynamic system including the motion equation, continuous equation, Cauchy strair. tensor and constitutive equation are given in [3]. The constitutive equation describing the stres. strain relation is as

$$
\sigma_{\mathrm{i}}=-\mathbf{P}(\rho, \mathrm{E})+\mathbf{S}_{\mathrm{i}}
$$

where $P$ is the average pressure, $S_{i}$ is the stress deviator, $E$ is the internal energy and $\rho$ is this specific volume.

Since the values of the stresses acting under ultrasonic treatment are considerably small, the following baro-tropic cubic equation was used to describe the pressure:

$$
\mathrm{P}=\mathrm{A} \Theta+\mathrm{B \Theta}^{2}+\mathrm{C}^{3} \text {, }
$$

where $\Theta$ is the cubic strain. The coefficients $A, B$ and $C$ are defined in $[4,5]$ for a number of materials.

The shear stresses are defined from the following equation of relaxation type:

$$
\dot{\mathrm{S}}_{1}=4 \mu\left(\dot{\varepsilon}_{1}^{\mathrm{T}}-2 \dot{\gamma}^{\mathrm{p}}\right) / 3 \text {, }
$$

where $\dot{\varepsilon}_{1}^{\mathrm{T}}$ is the total strain rate. The plastic shear rate is proposed to be defined taking into account the contributions from different level of material.

Plastic flow on micro-level is caused by evolution of dislocation continuum. In contrast in conventional model concepts not considering the plastic deformation at $\sigma<\sigma_{0.2}$, the proposed model assumes that any small disturbances cause the corresponding small plastic deformations. This approach has a great importance for ultrasonic loading, because the influence of a series of high frequency pulses (even at stresses below the technical yield point of material) can lead in accumulation of considerably high plastic deformation.

Total plastic deformation at each time-step of the loading is proposed to present as the sum of contributions from every dislocation fraction:

$$
\dot{\gamma}^{p}=\sum_{i} \Delta \dot{\gamma}^{p}, \quad \Delta \dot{\gamma}^{p}=\operatorname{gbNfP}_{i}\left(\tau_{s i}\right) v_{i}
$$

where $g=0.5$ is the orientation factor; $b$ is a Burgers vector; $N$ and $f$ are the dislocation density and the portion of movable dislocations correspondingly; $\mathrm{P}_{i}\left(\tau_{\mathrm{si}}\right)$ is the probability of motion of $i-\mathrm{th}_{\mathrm{i}}$ dislocation fraction at the stress $\tau_{\mathrm{si}}$ and the velocity $v_{i}$. The normal distribution of the defects over the starting stresses is

$$
P_{i}\left(\tau_{s i}\right)=\int_{\tau_{1-1}}^{\tau_{i}} \frac{1}{\delta \sqrt{2 \pi}} \cdot \exp \left[-\frac{\left(\tau_{s i}-\tau_{0}^{\prime}\right)^{2}}{2 \delta^{2}}\right] d \tau_{s i},
$$

where $\tau_{0}^{\prime}=\tau_{0}+\alpha \mu b \sqrt{N}$ corresponds to the yield stress taking into account appearance of remoti back stresses due to dislocation forest.

Expressions of the dislocation density $\mathrm{N}$, portion of movable defects $\mathrm{f}$ and their velocities $v_{\text {: }}$ taking into account Bauschinger's non-ideal effect, generation and deceleration of dislocations are given in [1] in details.

The total yielding stress of the materials under loading is proposed to be written taking into account formation and evolution of meso-substructures as:

$$
\tau_{0}^{\prime}=\tau_{0}+\alpha \mu b \sqrt{N}+K_{1}^{\prime} P_{1}\left(\gamma^{p}\right)+K_{2}^{\prime} P_{2}\left(\gamma^{p}\right)+K_{3}^{\prime} P_{3}\left(\gamma^{p}\right)
$$

where $\tau_{0}$ is the yield stress of the material before treatment; $K_{j}^{\prime}$ are the model parameters. describing the value of contribution from meso-level due to formation of corresponding meso. substructures; $\mathrm{P}_{j}\left(\gamma^{\mathrm{p}}\right)$ are the probabilities of these meso-substructures.

To test the state equations the calculations of $\sigma-\varepsilon$ diagrams were carried out for the soft steel under cyclic loading $\left(\dot{\varepsilon}^{\top}=10^{4} \mathrm{c}^{-1}\right)$. The calculated and experimental results are presented in Fig. 2a. The materials constants and parameters of the constitutive equation are given in [1]. 


\section{RESULTS OF NUMERICAL SIMULATIONS}

\subsection{Simulation of materials response to ultrasonic treatment}

The scheme of ultrasonic wave generation in the studied specimen is shown in Fig.la. Following this scheme the feeding of ultrasonic energy into the specimens realized by direct contact either with a converter or through a metal concentrator. This scheme allows to reach high enough stress values (upto fracture) in the specimens. At the same time the application of this scheme is limited by the resonance length of the systems.

In numerical simulations the boundary conditions at the output of the specimen are written as:

$$
\mathrm{U}(\mathrm{t})=\mathrm{U}_{\max } \sin \omega \mathrm{t}
$$

where $\omega$ is an angle velocity of the ultrasonic treatment; $t$ is the current time. The stress value at the free surface is equal to zero.

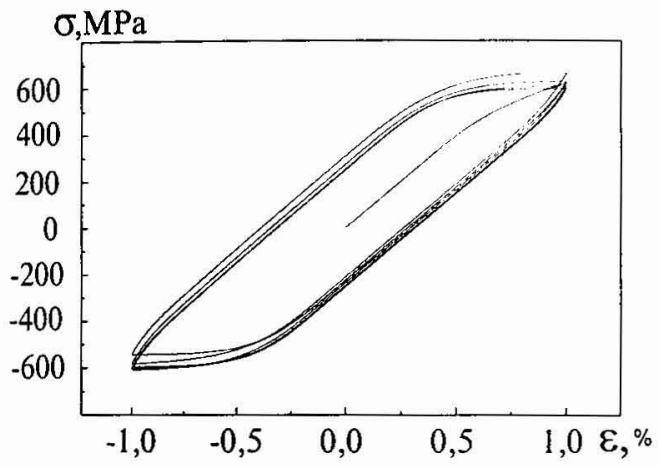

a)

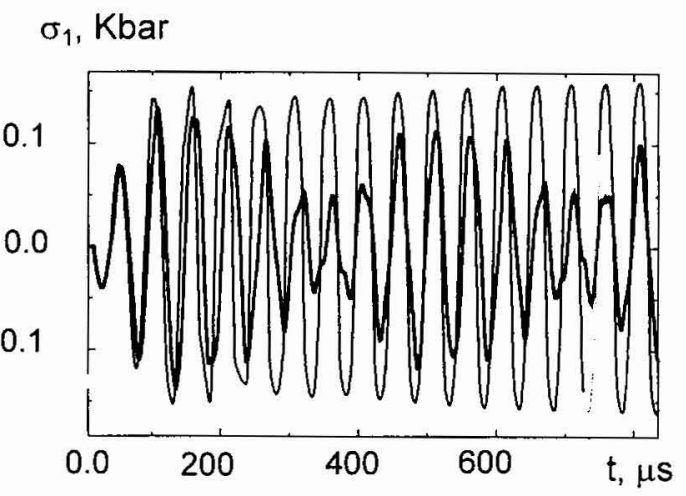

b)

Figure 2: Calculated stress-strain curve of mild steel under cyclic loading (a) and calculated stress-time history of mild steel under cyclic ultrasonic loading at various deviations from resonance length (b).

High frequency cyclic loading takes place, at which standing waves have to be formed in the system "magnetostrictive converter - concentrator specimen". In reality there are some energy redistribution due to assembling of the system parts, materials inhomogeneity, etc. Therefore the real process is in between the standing and the running waves. The amplitude of alternative stresses in ultrasonic waves is near to the yield stress and extremely sensitive to deviation from the resonance length of the system (Fig. 2b).

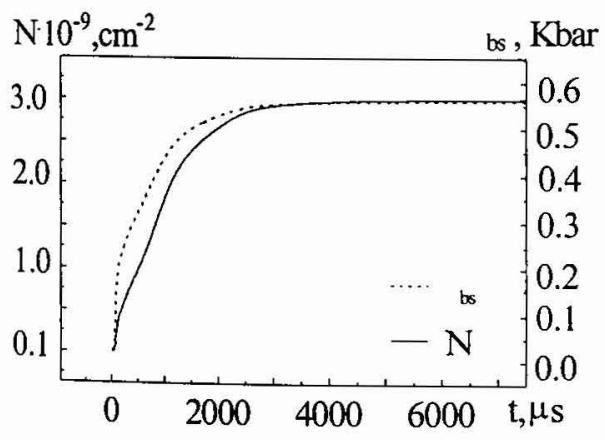

a)

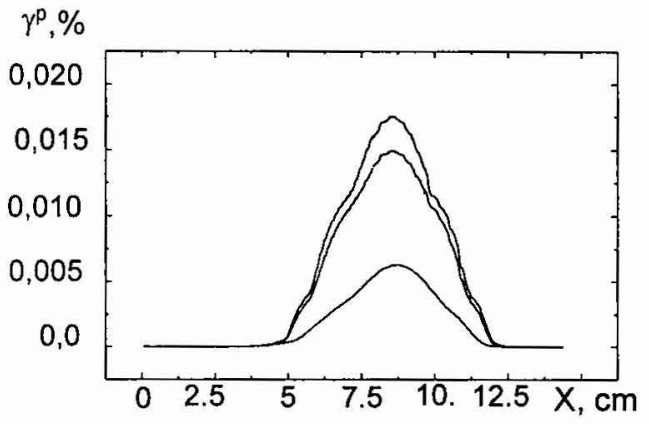

b)

Figure 3: Calculated dislocation density $N$ and remote back stress $\tau_{\text {bs }}$ (a) and distribution of plastic deformation with coordinates (b) under cyclic ultrasonic loading with $\xi_{\mathrm{m}}=20 \mu \mathrm{m}$. 
The calculations were carried out for the specimens made of soft steel subjected to the ultrasonic treatment.

The calculations showed that accumulation of plastic micro-strains is of essentially nonlinear character and connected with both the evolution of the defect structure on micro-level and the amplitude of the acting macro-stresses. Fig. 3 shows the calculated results for soft steel at different loading stages. This character of the dislocation accumulation is attributed to the influence of different factors.

Firstly, the two competing processes are simultaneously developed on micro-level in the material (Fig.3a). From one hand due to alternative stresses the dislocations are generated. accumulated and moved (plastic flow). From another hand the increase of dislocation density leads to development of remote back stresses, depressing the dislocation movement (hardening).

Moreover, accumulation of plastic deformations is of highly localized character (Fig. $3 \mathrm{~b}$ ). It is caused by standing waves, when the most intensive structural evolution goes on in the region of stress antinode. But under treatment the standing wave may result in considerable deviation from symmetric distribution of dislocation density relatively to the center of the specimen.

\subsection{Simulation of materials response to ultrasonic shock treatment}

The scheme of ultrasonic shock treatment is presented in Fig. Ib. The deforming tool is pressed to the specimen surface with the constant force $F_{N}$ and the ultrasonic vibrations are excited in the system. It ensures the high frequency shock treatment. The treatment results in decreasing the surface roughness and cold working layer upto several tens of microns in depth.
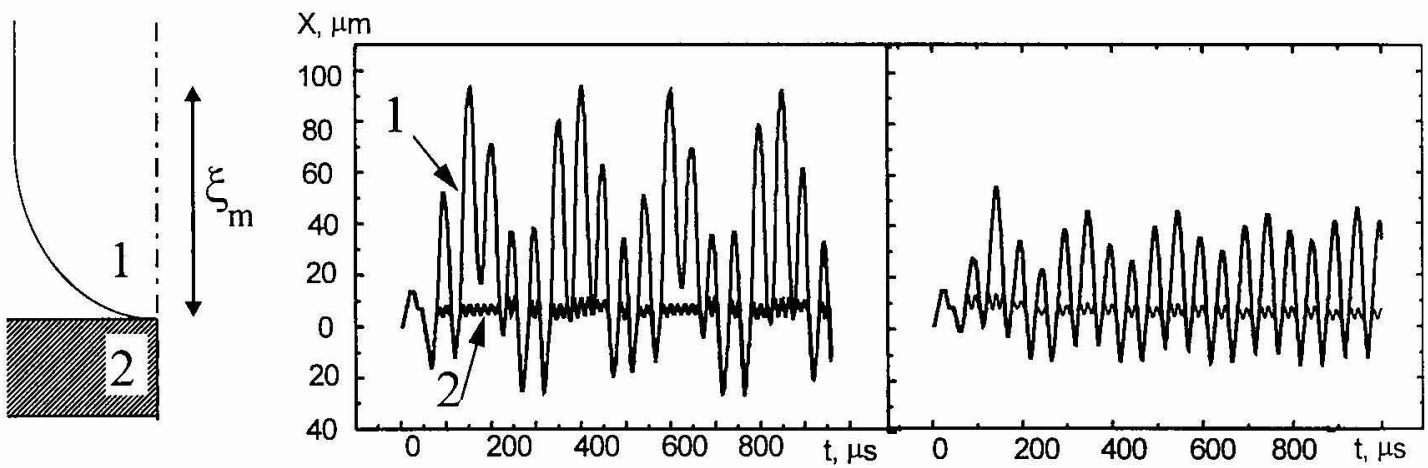

a)

b)

Figure 4: Displacement of tool (1) - specimen (2) interface under ultrasonic shock treatment at various amplitudes (a $\left.\xi_{\mathrm{m}}=20 \mu \mathrm{m}, \mathrm{b}-\xi_{m}=10 \mu \mathrm{m}\right)$.

The boundary conditions at the converter output is:

$$
\sigma(\mathrm{t})=\sigma_{\text {const }}+\sigma_{\max } \sin \omega \mathrm{t}
$$

where $\sigma_{\text {const }}$ is the stress due to the static pressing force $F_{N} ; \sigma_{\max }$ is the stress amplitude in the ultrasonic wave; $\omega$ is an angle velocity of the ultrasonic treatment; $t$ is the current time.

The way of motion of the deforming element depends on the loading parameters and inertial properties of the system. Fig.4 shows the time-dependence of the deforming tool displacements at the different amplitudes of ultrasonic treatment (the pressing force is $200 \mathrm{~N}$ ). The calculations showed that at lower ultrasonic amplitude (Fig.4b) the frequency of the shock influence is higher. but its amplitude is decreases. The interaction is of complicated non-harmonic character with the stress amplitudes initiating the plastic flow. Accumulation of plastic deformation (Fig.5a) is caused by the processes ongoing on micro-level (evolution of dislocation continuum) and on meso-level 
(development of meso-substructures, fragmentation of the crystals, rotation and displacement of the fragments).

Deforming elements of different shape, as well as different amplitudes of pressing force and ultrasound are used depending on the desirable effect of the treatment. For example at spherical deforming element the stress waves propagating into the surface layer are spherically attenuated. The cold worked layer upto several tens of microns in depth is formed (Fig.5b). The higher the stress amplitude, the deeper the cold worked layer. Usually the time of ultrasonic shock treatment is considerably less, than that of pure ultrasonic treatment. It is defined to obtain the maximum cold working and to avoid the fracture of the surface.

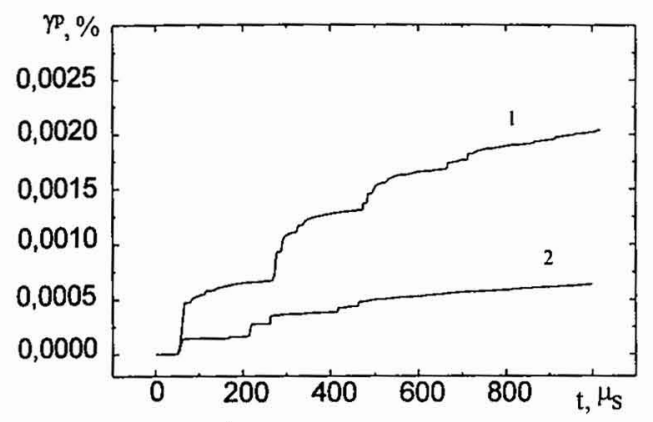

a)

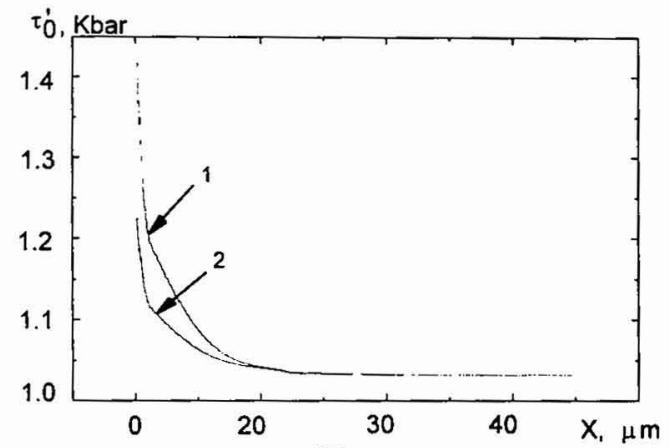

(b)

Figure 5: Accumulation of plastic deformation (a) and distribution of the total yielding stress (b) under ultrasonic shock treatment at various amplitudes $\left(1-\xi_{\mathrm{m}}=20 \mu \mathrm{m}, 2-\xi_{m}=10 \mu m\right)$.

At ultrasonic polishing the plane deforming element and small ultrasonic amplitudes are used. In this case due to the large contact area and small ultrasound amplitude the stresses do not cause plastic deformation in near surface layer and only micro-roughness on the surface is plastically deformed.

\section{CONCLUSION}

The necessity of investigation of materials response under different regimes of ultrasonic treatment still exists, because a wide range of new materials, methods of coating and surface treatment has recently appeared. The authors proposed a new dynamic model allowing to predict the materials response under ultrasonic treatment at different regimes. Development of plastic flow is described taking into account the contributions from different structural levels of the material. Numerical simulation of behavior of specimens made of soft steel at two different regimes of ultrasonic treatment was carried out. Both qualitative and quantitative agreement between the calculated and experimental results is obtained. The fitting up of each parameter of ultrasonic treatment (oscillation frequency and amplitude, duration of the treatment, geometry, etc.) as well as studying its influence on the deformation process (optimization of all the parameters) are not an easy task, which can be solved at the border of physics of plasticity, mechanics and numerical modeling.

\section{References}

[1] Makarov P.V., Mathematical multilevel model of elastic-plastic deformation of heterogeneous structures, Thesis of Physics-Mathematics Science Professor, Tomsk, 1995, 248 P.

[2] Makarov P.V., Balokhonov R.R., Romanova V.A. and Klimenov V.A., "Modelling of accumulation processes of microplastic deformations and damages in meso-volume of metals under ultrasonic loading", Mathematical Method in Physics, Mechanics and Mesomechanics of Fracture, Tomsk, 27-29 Aug., 1996, 63 P. 
[3]M.L.Wilkins, Calculations of Elastic-Plastic Flow. in B.Alder, S.Fernbach and M.Rotenberg (eds). Methods in Computational Physics, Vol. 3, Academic Press, New York, 1964, pp.211-263.

[4] Champion A.R. and Rohde R.W., Hugoniot equation of state and the effect of shock stress amplitude and duration on the hardness of hadfield steel, J. Appl. Phys., V.41, N5, 1970. pp. 2213-2222.

[5] Wallace D.C., Equation of state from weak shocks in solids, Physical review B.,V.22, N4, 1980, pp. 1495-1502. 